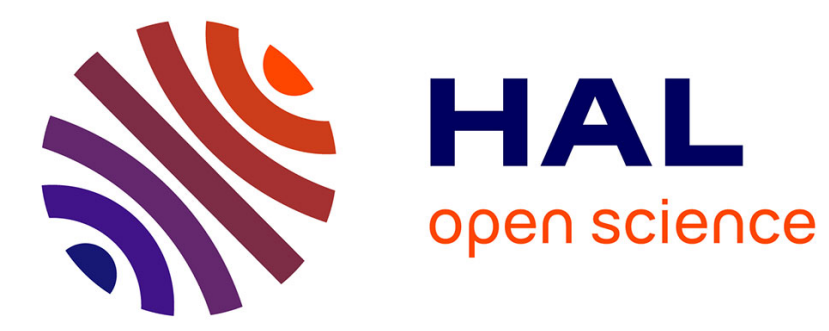

\title{
Industrial Collaborative Robotics Platform
}

Luis Vicente, Pedro Lomelino, Fernando Carreira, Francisco M. Campos, Mário J. G. C. Mendes, A. Luis Osório, J.M. F. Calado

\section{To cite this version:}

Luis Vicente, Pedro Lomelino, Fernando Carreira, Francisco M. Campos, Mário J. G. C. Mendes, et al.. Industrial Collaborative Robotics Platform. 22nd Working Conference on Virtual Enterprises (PROVE 2021), Nov 2021, Saint-Etienne, France. pp.567-576, 10.1007/978-3-030-85969-5_53 . emse03346511

\section{HAL Id: emse-03346511 https: / hal-emse.ccsd.cnrs.fr/emse-03346511}

Submitted on 25 Nov 2021

HAL is a multi-disciplinary open access archive for the deposit and dissemination of scientific research documents, whether they are published or not. The documents may come from teaching and research institutions in France or abroad, or from public or private research centers.
L'archive ouverte pluridisciplinaire HAL, est destinée au dépôt et à la diffusion de documents scientifiques de niveau recherche, publiés ou non, émanant des établissements d'enseignement et de recherche français ou étrangers, des laboratoires publics ou privés. 


\title{
Industrial Collaborative Robotics Platform
}

\author{
Luís Vicente $^{1}$, Pedro Lomelino ${ }^{1}$, Fernando Carreira ${ }^{1,3}$, Francisco M. Campos ${ }^{1}$, \\ Mário J. G. C. Mendes ${ }^{1,2}$, A. Luís Osório ${ }^{1}$, J. M. F. Calado ${ }^{1,3}$ \\ ${ }^{1}$ ISEL - Instituto Superior de Engenharia de Lisboa, Instituto Politécnico de Lisboa, \\ 1959-007 Lisbon, Portugal \\ ${ }^{2}$ CENTEC - Centre for Marine Technology and Ocean Engineering, Lisbon, Portugal \\ ${ }^{3}$ LAETA/IDMEC - Instituto de Engenharia Mecânica, Lisbon, Portugal \\ \{A42292, A43640\}@alunos.isel.pt, \{fernando.carreira, francisco.campos\}@isel.pt, \\ \{mario.mendes, luis.osorio, joao.calado\}@isel.pt
}

\begin{abstract}
Cyber-physical systems are not designed to integrate an industrial collaborative network when their integration with other systems is required. It is necessary to adopt a strategic model of integration and value creation that allows the interoperability of equipment supported by open technologies, based on the concepts underlying Industry 4.0. To this end, a conceptual information architecture is proposed to manage industrial robotic platforms based on a Cyber Device Bus design. The challenge is to contribute to an open technological framework involving computer systems, cyber-physical systems, and IoT elements in a logic of integration by adaptation without the need for specialized adapters. Adaptation occurs through the adoption of the Informatics System of Systems (ISoS) technological framework, providing an integrated serviceoriented (micro-services) view of technology elements and establishing cooperation between computer and cyber-physical systems under different responsibilities and based on a diversity of technological frameworks.
\end{abstract}

Keywords: Interoperability; Industrial Collaborative Network; Communication Platform; Systems of Systems.

\section{Introduction}

Increasingly, associations seek to increase flexibility and responsiveness to meet the individual requirements of each client. Industry 4.0 has demanded that physical processes interconnect with cyber components, defining cyber-physical systems (CPS), enabling an environment where the physical world merges with the cyber world [1]. From the point of view of information and computer science, new information technologies must be gradually applied on the shop floor, integrating CPS framed into architectures based on the Internet of Things (IoT) as a strategy to create a collaborative environment. The IoT represents a technological revolution where the goal is to connect independent devices (each having its computing and communication parts, technologically differentiated and possibly ownership from different responsibilities) 
in a network, through the establishment of a global communication system, providing them with the ability to communicate with each other $[2,3]$.

Currently, any process under the concept of smart factories is carried out using several enterprise information systems (EIS), such as supervisory control and data acquisition (SCADA) systems, manufacturing execution systems (MES), enterprise resource planning systems (ERP), human resource management systems (HRM) and customer relationship management systems (CRM), among others. In this context, it is essential to guarantee the cooperation between EIS and their interoperability in order to achieve an effective management structure of corporate systems. Collaboration between different EIS is hampered by the fact that they are often developed by different suppliers, which creates the need to integrate them into a single collaborative platform [1].

The ability to interconnect systems within a system of systems framework emphasizes the need for an innovative approach to organize the diversity of technological artifacts that may be under the responsibility of different entities. This approach amounts to providing intelligent and communication capabilities to all devices, thus driving automation and monitoring capacity [4]. Currently, the typical EIS framework of organizations is still built on automation islands, as a set of disparate systems for process automation in a given application domain [5].

This paper addresses industrial robotic platforms' management that consists of a collaborative industrial network connecting robots and automated systems. A conceptual information system architecture based on the Informatics System of Systems (ISoS) framework and architectural methodology to achieve that goal is proposed, which guarantees interoperability and allows easy collaboration between different EIS.

This article is organized as follows: section 2 analyses the state of the art of collaborative information architectures; section 3 describes the ISoS methodology; a conceptual information system architecture based on the ISoS approach to achieve a collaborative platform of industrial robots is presented in Section 4. Finally, the conclusions and recommendations for future work are summarized in Section 5.

\section{State of the Art}

In the last century, the added value for industries came from the development of the mechanical domain. Today, the computer domain made possible through the evolution of information technologies has become the main driver of the development of organizations [6]. The growing mass customization requires that large volumes of data be simultaneously exchanged in real-time between different organizational systems. Thus, the challenge is to achieve direct communication between the Fieldbus and the application layer that promotes interoperability between all software and physical processes. This communication paradigm translates into a communication infrastructure over the internet. Each node represents a computer or CPS within the organization that can communicate with many other nodes (Fig. 1), thereby creating an environment based on collaborative processes. In this interwoven network, machines 
and applications need to communicate in the same language, coexist in the same infrastructure, and comply with multiple requirements [7].

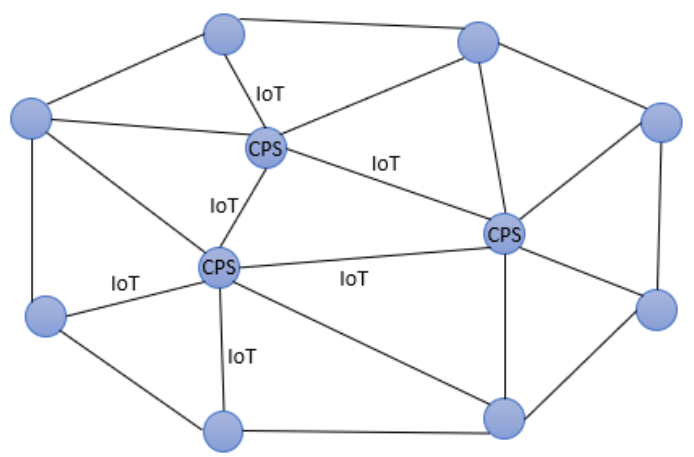

Fig. 1. Collaborative information network.

Usually, computers and CPS are not designed to cooperate when the goal is the integration (interoperability) with other systems, potentially from a different business organization, seller, or supplier. When two or more systems under different responsibilities communicate, their managers must agree on the interfaces to use or provide access to a repository (database) through which systems can share data. Despite being a common practice to share information between systems, the access to databases generates strong dependencies between them, reflected in the dependence on changes, which are difficult to manage, e.g., in the face of a change to the database schema [5]. In order to avoid strong dependencies in networks, mediation strategies are adopted involving specialized computer systems to establish "bridges" through the "Hub and Spoke Integration" model [8] or the organization/company service bus (Enterprise Service Bus - ESB) [9, 10]. However, the use of mediation systems, e.g., ESB, contributes to strengthening the technological dependence. Often, these systems centralize dependencies of different technological systems and do not support a more competitive framework of responsibilities, in which exchanging systems or parts of systems would be seamless [11]. From the above, it can be concluded that system diversity hinders traditional systems from achieving the goals of Industry 4.0.

Communication on an industrial network is performed through a cyber platform commonly called Cyber Device Bus. To ensure communication between different systems, a computer systems architecture based on the design of an open Cyber Device Bus is necessary, with the following requirements: provide an open computational platform, ensure collaboration and ensure interoperability between computational entities and/or cyber-physical systems [12]. The design of this platform and the underlying architecture requires a set of non-functional requirements, typical of this type of open and distributed systems, namely: interoperability, transparency in location, fault tolerance, data, and communication security and scalability. In addition to the nonfunctional requirements, further requirements are needed, such as resilience, performance, portability, and substitutability [13].

In recent years, there has been much research into new collaborative reference architectures for Industry 4.0. However, works on conceptual architectures often lack a 
physical implementation, and application examples do not typically generalize to other systems [14].

There are currently several initiatives aimed at developing standardized system architectures. As an example, the German Reference Architecture Model Industry (RAMI 4.0) (DIN 2016) [15] proposes a reference model focused on system hierarchy, vertical communication network, and life cycle management, while the American Industrial Internet Reference Architecture (IIRA) [16] aims to achieve global adaptation and collaborative autonomy in an industrial Internet of Things (IIoT) system.

In the current technological landscape, the trend is towards a concentration of functionalities that, depending on the risk, are only accessible to proprietary technological frameworks (SAP, IBM, ORACLE, Microsoft, Amazon, Google, among others). These approaches, which include the concept of micro-services [17], do not convey relevant innovation in the context of a Service-Oriented Architecture (SOA) [18], so they are unlikely to promote integrated approaches that support processes in the digital age. There are currently several approaches to perform interoperability tasks between CPS, but these are proprietary systems. The diversity of techniques means that to perform changes or upgrades in the system, the customer is very dependent on the proprietary organization. Thus, the existing standards do not guarantee the substitutability of systems or elements of a computer system with potentially more competitive alternatives. In other words, the current standards are not complete in the sense of guaranteeing the exchangeability of systems or computer system elements with potentially more competitive alternatives [19]. The lifecycle of a CPS may span decades, depending on its application domain. Thus, it is necessary to ensure those information architectures and their associated support services are available throughout the CPS lifecycle. Current approaches are struggling with the problem of technological dependency, known as the vendor lock-in situation. It is well known that public and private entities experience difficulties developing their innovation processes when they depend on technological devices, from the IoT level to the decision support services [11].

To avoid problems associated with vendor dependency, many companies using CPS have recently chosen to keep the development of their information architecture in-house as a means of avoiding potential risks inherent in commercial architectures. This strategy gave rise to open-source solutions, e. g. Papyrus (2020) [20] and Capella (2020) [21], which allow companies to develop their own customized information architectures. Several open-source initiatives have also been launched, as evidenced by the efforts of NASA, the Japanese Science and Technology Agency, and several consortia of industry and academia in Europe in creating open-source tools to assist in the development of collaborative information architectures [22].

More cooperative EIS environments based on information/knowledge are needed to meet current business demands. The cooperative EIS need contrasts with today's information architectures in most applications, which simply connect devices and can hardly support collaborative optimization for production systems. Other than that, information architectures should promote a relationship chain where all computers and CPSs provide support for knowledge construction, process monitoring, decision support, requirements management, and control [1]. 
There are currently numerous technological approaches that can be used to build a collaborative information architecture ensuring interoperability between various EIS. However, most of these are proprietary approaches that are difficult to budget and are not based on previously validated models. Most technological artifacts are not based on standard or reference models, which implies that the market does not moderate their cost. Thus, any change to the system, such as an integration requirement, is dependent on the involvement of those responsible for it, at a price that has no reference to be supported [23]. The fact that state-of-art relies on unique computer systems developed as custom software without a formal framework and open modularity foundations has been a barrier to sustainable innovation.

\section{Informatics System of Systems Approach}

Today's industrial challenges have made production structures more complex and require new management and organizational strategies that offer greater flexibility, agility, efficiency, and effectiveness. In order to meet this challenge, remote and intelligent control and monitoring systems must be developed that deal with the distinctive functionalities of sensor and actuator networks, monitor hardware and software, and connect with production management and planning. These smart systems require high automation and information processing levels, allowing for rapid response to shop floor changes. An outcome of coupling smart supervisory with real-time decision support systems is the reduction of lead-times and costs on the shop floor, achieved through flexibility improvement of the production processes and by enhancing management control, which is supported by new decision support tools based on self-learning approaches and smart analytics. Hence, this paper addresses the implementation of a service-oriented Cooperation Enabled Services (CES) as a modularity abstraction framework to reduce the technology dependencies and empower the modeling and intelligence capabilities.

The Informatics System of Systems (ISoS) [11] founds an open technological framework and incorporates the concept of Open Adaptive Coupling Infrastructure (OACI) to facilitate interoperability. This framework has been applied in several systems to structure technological artifacts of a company/organization, e.g., the Brisa tolls, speed control network (ANSR/SINCRO), and the automatic payment control in service area networks [23]. In the ISoS framework, a computational or cyber-physical element of an Informatics System (Isystem) is structured as the composition of one or more CES. A CES models a composite of Service elements. An innovative aspect of the ISoS model is that a CES is made up of services (computational parts of CPS or computer systems) that can be developed under any technological framework. The ISoS model allows any service belonging to an Isystem to be instantiated as an element of a computer or cyber-physical system. ISoS makes it possible for an organization/company to cooperate with any other Service of a CES from another Isystem without the need for specialized adapters.

The aim of developing ISoS is to contribute to an open technological framework that encompasses computer systems, CPS, and IoT elements and promotes adaptation without special adapters. Instead, adaptation takes place by obtaining meta-data on the service elements and through cooperation between computer systems and CPS under 
different responsibilities and on the basis of a diversity of technological frameworks $[11,25]$.

The proposed OACI as a loose coupling strategy based on the CES and Isystems concepts unifies the factory of the future computational infrastructure allowing the separation (decouple) of intelligent processes sharing a common distributed computational infrastructure (coordination, security, scalability, fault tolerance, quality of services reliability, and costs moderation through a multi-supplier framework). The capability of establishing hybrid computational execution environments on-premises and on the cloud, aligned with the microservices dynamics, makes the proposed approach scalable (elasticity) and prone (open) for emerging intelligent services and facilitates business intelligence applications integration.

\section{Information System Architecture for Collaborative Networking}

In the industry 4.0 approach, robot control and supervision system can be considered as a CPS, henceforth referred to as a robotic cyber-physical system (CPS-R). It is essential to reorganize them on a computational platform based on the internet to achieve a global collaborative network that allows covering all EIS, including CPS. The exchange of information between systems creates a collaborative, productive environment. In this work it is defined a system architecture based on the open technological framework ISoS, addressing the use of CPS-R to perform the collaboration and interoperability between CPS and EIS in an industrial plant with robots. Fig. 2 shows the context of the adoption of the ISoS framework and the concept of a Cyber Device Bus, forming a computational platform that integrates computational and/or cyber-physical entities. Notice that the presented robot is illustrative only. The information system architecture can be applied to any robot configuration.

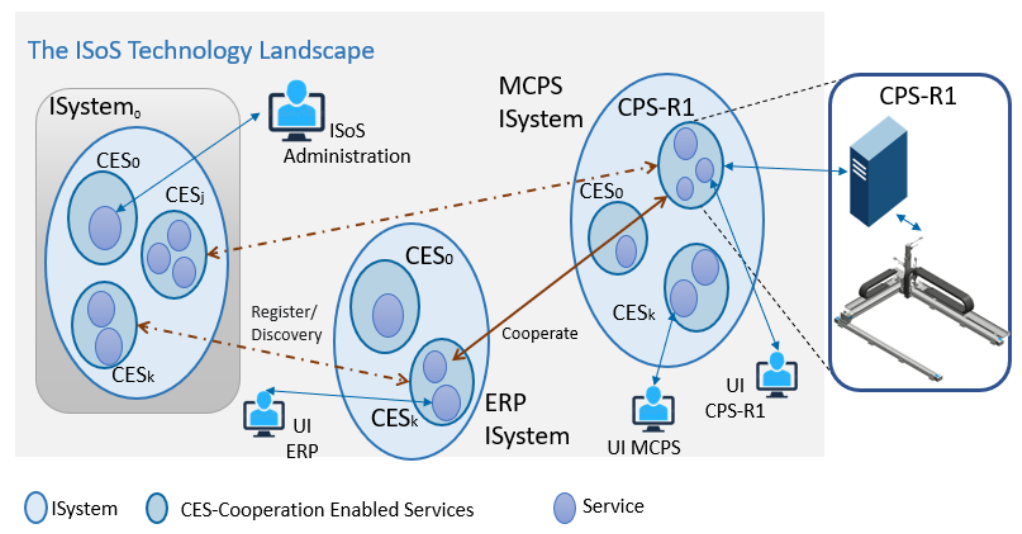

Fig. 2. Collaborative network based in the ISoS framework using CPS-R elements.

The framework of the collaborative network represented in Fig. 2 is based on the ISoS system approach, where the ISytem 0 meta-system translates the strategy of 
integration and coordination of the set of technological systems that make up an organization.

In this approach, the CPS-R constitutes a CES that in turn is composed of Services that are constituted as computational elements that guarantee its operation and the availability of functionalities to be accessed by other services, the cyber-physical system, or other computer systems. The CPS-R $\mathrm{R}_{\mathrm{CES}}$ occurs as an element of the ISystem MCPS (A computerized management system for cyber-physical systems). This ISystem may be composed of other CES elements associated with other CPS of industrial robots, which exist or may be added to the organization.

This approach allows you to integrate The CPS with the organization's computer systems, e.g., an ERP computer system can obtain data from a CPS. Each computer system, according to the ISoS approach, will constitute an ISystem, which is in turn composed of CES. In fact, the CES elements are a composition of independent computational elements to which we call the Service. Thus, with this approach, the access of an ERP system modelled by an ISystem is considered as an ISystem to a service of the CPS, as shown in Fig. 2.

Communication in the proposed approach can be carried out between two services, from any CES, even if they are in conformity with different systems. A Service uses

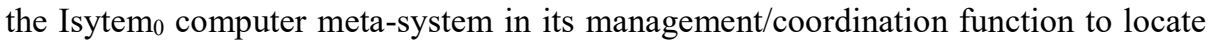
each computational element, that is, the information that allows access to a particular service.

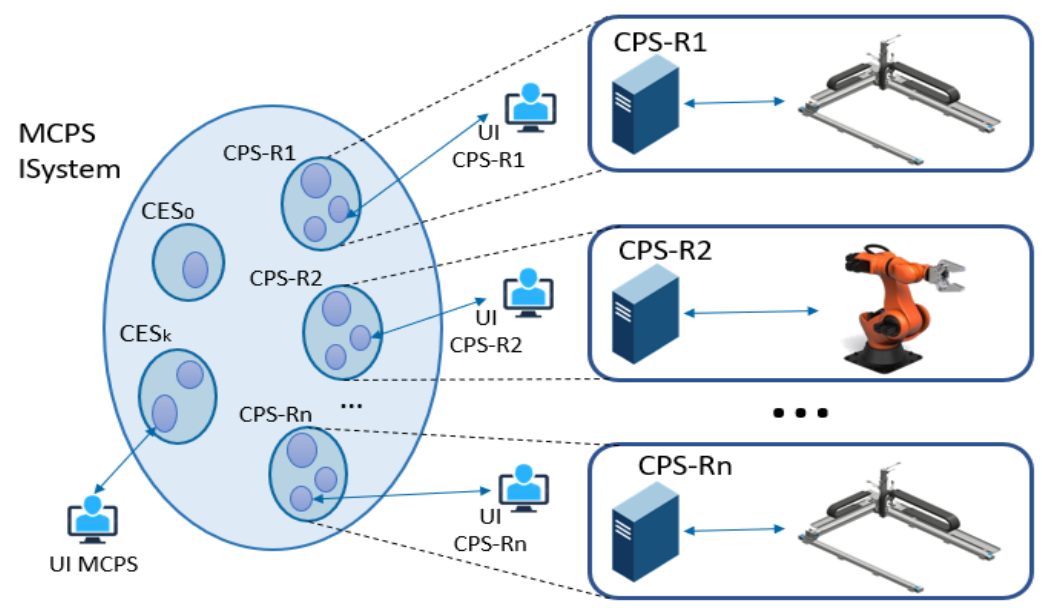

Fig. 3. Isystem architectures to perform interoperability with several CPS-Rs.

Additionally, with this architecture may be developed user interfaces (UI), for example, a web interface, from which a person can have access to information from the various services and in specific relevant aspects of the desired CPS.

Usually, processes are performed by several robots that work collaboratively and share data between them or control and supervision systems. Thus, this approach allows to be extended with the creation of new services associated with existing Isystems or new Isystems to take into account the several CPS-R, i.e., with the CPS-R1, CPS-R2, 
..., CPS-Rn, being $\mathrm{n}$ the number of robotic systems that may come to incorporate into the organization (Fig. 3).

This computational platform allows responding to the new service-oriented functionality management paradigm, providing an industrial collaborative network that guarantees interoperability, security, and scalability in accessing and exchanging data. With this computational architecture, an infinite number of computers and CPS can be integrated. At any time, a new service, computer system, or cyber-physical system can be added, integrating it into the organization's collaborative network.

Through the ability to exchange information between services, machine-to-machine communication is promoted, allowing two or more industrial robots to exchange information autonomously with each other, without the need for human intervention, using this computational platform. Because this architecture is internet-based, this allows the integration of all CPS of an organization regardless of their location. In this way, even in different facilities, the CPS can communicate with each other and with all computer systems, thus ensuring a global collaborative network.

\section{Conclusion}

In this article, a conceptual information architecture is proposed to manage industrial robotic platforms based on the design of a Cyber Device Bus, using the ISoS technological framework. The structure of the proposed architecture was built to create a collaborative industrial network through the reorganization of all systems that incorporate an organization, allowing interoperability between systems. This architecture translates into a computational platform that covers an infinite number of EIS, as well as an infinite number of CPS, promoting a collaborative environment. The computational platform presented allows users to have an overview of the entire organization, allowing access to all information from both computer systems and CPS through the various UI. By adopting the architecture presented throughout the organization, a service-oriented colouring mechanism is provided, allowing customers, manufacturing processes, and suppliers to be integrated, making it possible to respond to the high rate of customization required by the market. Future work should focus on the implementation of the architecture presented with a view to its validation in the construction of a collaborative industrial network.

Acknowledgments. This work was supported by the project POCI-01-0247-FEDER039764 under the Program PORTUGAL2020.

\section{References}

1. Wang, J., Xu, C., Zhang, J., Bao, J., Zhong, R.: A collaborative architecture of the industrial internet platform for manufacturing systems. Robot. Comput. Integr. Manuf. 61, 101854 (2020)

2. Documentos Estratégicos Análise de documentos estratégicos e de boas práticas 
internacionais com vista à identificação das melhores e mais eficientes praticas e processos no âmbito da Indústria 4.0, https://hub.pme-digital.pt/wpcontent/uploads/2020/08/PMED.089.pdf, (2019).

3. Malik, P.K., Sharma, R., Singh, R., Gehlot, A., Satapathy, S.C., Alnumay, W.S., Pelusi, D., Ghosh, U., Nayak, J.: Industrial Internet of Things and its Applications in Industry 4.0: State of The Art. Comput. Commun. 166, 125-139 (2021)

4. $\quad$ Vargas, I.G., Gottardi, T., Teresinha, R., Braga, V.: Approaches for integration in system of systems: A systematic review. In: Proceedings - 4th International Workshop on Software Engineering for Systems-of-Systems, SESoS 2016. pp. 32-38. Association for Computing Machinery, Inc, New York, (2016)

5. Calado, J., Osório, L.A., Prata, R.: An adaptive IoT management infrastructure for ecoTransport networks. In: IFIP Advances in Information and Communication Technology. pp. 285-296. Springer New York LLC (2015)

6. $\quad$ Ding, K., Zhang, Y., Chan, F.T.S., Zhang, C., Lv, J., Liu, Q., Leng, J., Fu, H.: A cyberphysical production monitoring service system for energy-aware collaborative production monitoring in a smart shop floor. J. Clean. Prod. 297, 126599 (2021)

7. Coito, T., Martins, M.S.E., Viegas, J.L., Firme, B., Figueiredo, J., Vieira, S.M., Sousa, J.M.C.: A Middleware Platform for Intelligent Automation: An Industrial Prototype Implementation. Comput. Ind. 123, (2020)

8. Pels, E.: Optimality of the hub-spoke system: A review of the literature, and directions for future research. Transp. Policy. (2020)

9. IBM Cloud Education: What is an ESB (Enterprise Service Bus)? I IBM, https://www.ibm.com/cloud/learn/esb

10. Bhadoria, R.S., Chaudhari, N.S., Tharinda, V.: Analyzing the role of interfaces in enterprise service bus: A middleware epitome for service-oriented systems. Comput. Stand. Interfaces. 55, 146-155 (2018)

11. Osório, L.: Collaborative Networks as Open Informatics System of Systems (ISoS), PhD Thesis, University of Amsterdam, (2020)

12. Panetto, H., Iung, B., Ivanov, D., Weichhart, G., Wang, X.: Challenges for the cyberphysical manufacturing enterprises of the future. Annu. Rev. Control. 47, 200-213 (2019)

13. Morel, G., Pereira, C.E., Nof, S.Y.: Historical survey and emerging challenges of manufacturing automation modeling and control: A systems architecting perspective. Annu. Rev. Control. 47, 21-34 (2019)

14. Biffl, S., Gerhard, D., Lüder, A.: Introduction to the multi-disciplinary engineering for cyber-physical production systems. In: Multi-Disciplinary Engineering for Cyber-Physical Production Systems: Data Models and Software Solutions for Handling Complex Engineering Projects. pp. 1-24. Springer International Publishing (2017)

15. Bousdekis, A., Lepenioti, K., Ntalaperas, D., Vergeti, D., Apostolou, D., Boursinos, V.: A RAMI 4.0 view of predictive maintenance: Software architecture, platform and case study in steel industry. In: Lecture Notes in Business Information Processing. pp. 95-106. Springer Verlag (2019)

16. Pedone, G., Mezgár, I.: Model similarity evidence and interoperability affinity in cloudready Industry 4.0 technologies, (2018)

17. Sjödin, D., Parida, V., Kohtamäki, M., Wincent, J.: An agile co-creation process for digital servitization: A micro-service innovation approach. J. Bus. Res. 112, 478-491 (2020)

18. Niknejad, N., Ismail, W., Ghani, I., Nazari, B., Bahari, M., Hussin, A.R.B.C.: Understanding Service-Oriented Architecture (SOA): A systematic literature review and directions for further investigation, (2020)

19. Osório, A.L., Camarinha-Matos, L.M., Afsarmanesh, H., Belloum, A.: On Reliable Collaborative Mobility Services. In: IFIP Advances in Information and Communication Technology. pp. 297-311. Springer New York LLC (2018) https://doi.org/10.1007/9783-319-99127-6_26 
20. Eclipse Papyrus TM Modeling environment, https://www.eclipse.org/papyrus/

21. Model Based Systems Engineering | Capella MBSE Tool, https://www.eclipse.org/capella/

22. Vara, J.L., Ruiz, A., Blondelle, G.: Assurance and certification of cyber-physical systems: The AMASS open source ecosystem. J. Syst. Softw. 171, (2021)

23. Osório, A.L., Camarinha-Matos, L.M., Dias, T., Tavares, J.: Adaptive Integration of IoT with Informatics Systems for Collaborative Industry: The SITL-IoT Case. In: IFIP Advances in Information and Communication Technology. pp. 43-54. Springer New York LLC (2019) https://doi.org/10.1007/978-3-030-28464-0_5

24. Osório, A.L., Camarinha-Matos, L.M., Afsarmanesh, H., Belloum, A.: Towards a Mobility Payment Service Based on Collaborative Open Systems. In: IFIP Advances in Information and Communication Technology. pp. 379-392. Springer New York LLC (2019) https://doi.org/10.1007/978-3-030-28464-0_33

25. Calado, J., Osório, L.: Dynamic integration of mould industry analytics and design forecasting. IFIP Adv. Inf. Commun. Technol. vol. 506, pp.649-657 (2017) 